\title{
DO PARADIGMA INDIVIDUALISTA À DIMENSÃO SOCIOAMBIENTAL: UM BREVE ESTUDO SOBRE A FUNÇÃO DOS CONTRATOS DO DIREITO BRASILEIRO
}

FROM THE INDIVIDUALIST PARADIGM TO THE SOCIO-ENVIRONMENTAL DIMENSION: A BRIEF STUDY ON THE FUNCTION OF CONTRACTS OF BRAZILIAN LAW

\section{Bernardo José Pinto de Mello e SILVA FILHO'}

ISSUE DOI: $10.21207 / 1983.4225 .503$

\section{RESUMO}

O presente estudo trata da evolução do entendimento acerca da função dos contratos dentro do Direito brasileiro. Por meio desta pesquisa objetiva-se verificar as transformações por que passou a função dos contratos na sociedade desde Código Civil de 1916, quando o caráter excessivamente patrimonialista e individualista da codificação inviabilizou a concretização de uma função social do contrato, até o atual paradigma de crise ecológica, quando emerge a dimensão ambiental do contrato e passa a se falar em uma função socioambiental, passando antes disso pela reformulação propiciada pela constitucionalização do Direito Civil, pela mudança de concepção de propriedade e pelo advento do Código Civil de 2002, a partir do qual se consagra a função social dos pactos jurídicos bilaterais. $\mathrm{O}$ trabalho possui

\footnotetext{
${ }^{1}$ Graduando do da Faculdade de Direito da Universidade Federal do Ceará (UFC). Estagiário da Defensoria Pública Estadual do Ceará. Email: bernardojpmsf@gmail.com
} 
caráter bibliográfico e documental. Constata, por fim, a grande sensibilidade dos contratos às transformações sociais e econômicas, bem como a sua posição de instrumento-chave no enfrentamento da crise ambiental.

Palavras-chave: Direito Civil. Contratos. Individualismo. Função social. Função socioambiental.

\section{INTRODUÇÃO}

É inegável a relevância dos contratos em todas as esferas da vida humana. Não é exagero dizer que quase todos os atos da vida civil se dão pela via contratual, obviamente quando se leva em conta apenas os negócios bilaterais. Definir esse instituto jurídico não é uma tarefa simples, porquanto o "matiz ideológico do contrato é pintado segundo a época e a conjuntura social em que ele é celebrado"2, logo, é fundamental determinar para que contexto histórico e social essa conceituação é requisitada.

O objeto de apreciação do presente trabalho não será, todavia, a definição de contratos, mas a função que lhe compete dentro da sociedade, muito embora a análise desse papel a ser desempenhado trará subsídios para caracterizá-los. Delimita-se o campo de estudo deste artigo ao Direito pátrio, apesar de que em dado momento exigir-se-á um exame do direito estrangeiro para fins de contextualização do estudo acerca do objeto principal. Far-se-á uso de fontes bibliográficas e documentais, essencialmente.

Estruturou-se a pesquisa em três tópicos basilares, que correspondem aos três estágios por que passa a função dos contratos: o paradigma individualista, a função social e a função socioambiental.

\section{PARADIGMA INDIVIDUALISTA}

Para uma melhor compreensão do individualismo em matéria contratual no Direito pátrio, deve-se fazer, primeiramente, uma digressão histórica à época da França pós-revolucionária, afinal, uma das codificações que mais exerceram influência no nosso Código Civil de 1916, o Código Napoleônico, surge nesse período e, como se sabe, o mencionado

\footnotetext{
${ }^{2}$ GAGLIANO, Pablo Stolze; PAMPLONA FILHO, Rodolfo. Novo Curso de Direito Civil: Contratos: teoria geral. 9. ed. São Paulo: Saraiva, 2013. 4 v. p. 40.
} 
diploma legal francês "serviu como modelo para a codificação de grande parte dos países do mundo ocidental que deixaram de acolher o sistema jurídico da common law" 3.

\subsection{O CONTRATO NA CODIFICAÇÃO CIVIL DA FRANÇA: O MODELO CLÁSSICO}

Dentro de um contexto pós-revolucionário, onde uma elite econômica excluída das decisões políticas finalmente ascende ao poder e em cuja memória guarda lembranças nada agradáveis da abusiva e recorrente intervenção estatal, nasce uma nova ordem jurídica. Trata-se da França na entre o final do séc. XVIII e começo do séc. XIX, período no qual está inserido um dos acontecimentos mais célebres de toda a História da humanidade: a Revolução Francesa, que, dentre outras consequências, "significou o triunfo da concepção econômica liberal de par ao estabelecimento das liberdades individuais conferidas por lei" ${ }^{4}$. Em linhas gerais, é essa a conjuntura na qual surge o Código Civil Francês de 1804.

No chamado Código Napoleônico, percebe-se claramente a incorporação dos ideais burgueses: liberdade, igualdade e fraternidade, bem como de um slogan célebre "deixai fazer, deixai passar". Liberdade para contrapor a ingerência excessiva do Estado, igualdade para afastar os privilégios da realeza e do clero, e, por fim, laisser faire, laisser passer para fomentar a livre iniciativa e o liberalismo econômico. Os mecanismos jurídicos tinham, consequentemente, o escopo de fazer sucumbir integralmente o Ancien Régime e instituir uma nova ordem liberal burguesa.

Muito provavelmente, o contrato é o instituto do Direito que mais deixou transparecer os anseios da burguesia, afinal, é pela via contratual, em regra, que se dão as transações mercantis, e uma classe desde sempre vocacionada para o comércio não poderia deixar de dar uma especial atenção a esse instrumento. Logo, a teoria contratual, à época, era fortemente marcada por traços individualistas e norteada por um modelo liberal, como não deixam dúvidas as suas características marcantes.

\footnotetext{
${ }^{3}$ SANTOS, Antonio Jeová. Função social do contrato: lesão e imprevisão no CC/2002 e no CDC. 2. ed. São Paulo: Método, 2004. p. 27.

${ }^{4}$ Ibidem, p. 31.
} 


\subsubsection{CARACTERÍSTICAS DO MODELO CLÁSSICO DE CONTRATO}

Em trabalho de rara precisão e didática, Borges ${ }^{5}$ explicita as particularidades da compreensão clássica do contrato:

a) Destinatário ideal: um sujeito destacado dos demais indivíduos da sociedade e concebido de modo abstrato, "formalmente igual ao outro contratante e livre para contratar e para estabelecer, com base em sua vontade, o conteúdo do contrato".

b) Segurança jurídica: princípio e objetivo da mais elevada estima, de modo que esse valor veio a se tornar uma verdadeira exigência das partes do contrato.

c) Antagonismo de interesses entre as partes: não se vislumbra um intercâmbio construtivo entre os interesses dos sujeitos contratantes.

d) Igualdade jurídica e formal: ideia de que todos são iguais perante a lei e que por isso devem estar submetidos aos mesmos rigores do Direito, ou seja, as partes devem ser vistas em posições semelhantes, sem considerar os fatores sociais e econômicos que as envolvem.

e) Intangibilidade: diz respeito à impossibilidade de se alterar o conteúdo do contrato a não ser por um novo pacto entre as partes, impedindo, assim uma modificação unilateral.

f) Obrigatoriedade: o contrato faz lei inter partes, isto é, possuem força jurídica vinculante, por isso devem ser observados (pacta sunt servanda). Como bem lembra Gagliano e Pamplona Filho (2013, p. 75), "de nada valeria o negócio, se o acordo firmado entre os contraentes não tivesse força obrigatória".

g) Relatividade: os direitos e obrigações decorrentes do contrato são oponíveis somente entre as partes contratantes, ou seja, eram relativos apenas aos contraentes, o que implica dizer também que à coletividade era imposto um "dever geral de abstenção".

\footnotetext{
${ }^{5}$ BORGES, Roxana Cardoso Brasileiro. Função ambiental do contrato: proposta de operacionalização de princípio civil para a proteção do meio ambiente. Revista de Direito Ambiental. São Paulo: Revista dos Tribunais, ano 13, n. 49, jan/mar, 2010.
} 
h) Mínima ingerência estatal: o papel do Estado se resumia a praticamente garantir o cumprimento dos acordos, limitando ao máximo seu campo de intervenção.

Fazendo-se uma interpretação conglobante das características acima elencadas, percebe-se, sem muito esforço, que havia um verdadeiro império da autonomia da vontade. Todos aqueles elementos vieram a contemplar e fortalecer este princípio, que, segundo a doutrina tradicional não ignorada por Tartuce ${ }^{6}$, ainda pode ser subdividido em duas vertentes: liberdade de contratar, traduzida na faculdade de escolha da pessoa com a qual se deseja firmar o acordo, e em liberdade contratual, que aponta para o direito de estipular o conteúdo do contrato.

Destaque-se, igualmente, que o contrato, mesmo à época, também era revestido por uma função - a dita função clássica dos contratos -, mas que, bem diferente da função social que ainda será analisada, significava tão-somente "gerar obrigações válidas a partir de acordos de vontade, que fazem nascer uma relação de imputação [...], estabelecida por razões de política jurídica, com efeitos determinados e limitados"7.

\subsection{A FUNÇÃO DOS CONTRATOS NO CÓDIGO CIVIL DE 1916}

A concepção de contrato adotada pelo Código de Beviláqua, assim como a muitos institutos dessa codificação, sofre, naturalmente, notável influência do Código Civil Francês de 1804, como se confirma pela doutrina de Barroso $^{8}$, que diz que "as doutrinas individualista e voluntarista, consagradas pelo Código Napoleônico (1804) e incorporadas pelas codificações do século XIX, repercutiram sobre o Código Civil brasileiro de 1916". Portanto, as propriedades acima mencionadas servem, mutatis mutandis, para caracterizar os contratos dentro da ordem civilista do Brasil durante boa parte do séc. XX.

\footnotetext{
${ }^{6}$ TARTUCE, Flávio. Teoria Geral dos Contratos: Os princípios contratuais no Código Civil de 2002. In: Direito Civil: Teoria Geral dos Contratos e Contratos em espécie. 8. ed. São Paulo: Método, 2013. Cap. 2. p. 55.

${ }^{7}$ BRANCO, Gerson Luiz Carlos. Função social dos contratos: interpretação à luz do Código Civil. São Paulo: Saraiva, 2009. p. 02.

${ }^{8}$ BARROSO, Luís Roberto. Curso de Direito Constitucional Contemporâneo: Os conceitos fundamentais e a construção do novo modelo. 3. ed. São Paulo: Saraiva, 2012. p. 80-81.
} 
O Código Civil de 1916 proporcionava, dessa forma, dentro do campo dos negócios jurídicos, extensa liberdade de contratação e estipulação contratual, já que estava pautado por uma disciplina do contrato fundamentada no modelo da autonomia da vontade. Entretanto, apesar de vasta, a autonomia da vontade tinha, sim, limitações, as quais estavam relacionadas basicamente a questões de ordem pública ${ }^{9}$, como era o caso do artigo 115, que assim dispunha: "São lícitas, em geral, todas as condições, que a lei não vedar expressamente. Entre as condições defesas se incluem as que privarem de todo efeito o ato, ou o sujeitarem ao arbítrio de uma das partes"10.

Novamente pela lição de Branco"11, entende-se que "o contrato acaba por ser considerado fenômeno elementar da ordem social, e o princípio da 'autonomia da vontade' possui utilidade social em razão da necessidade de servir à lei da oferta e da procura". Percebe-se, assim, que o contrato serve à sociedade na medida em que facilita a dinâmica comercial.

Outrossim, para o mesmo autor acima citado, os acordos de vontades, na medida em que abrem a oportunidade para as partes estabelecerem normas entre si, dão origem a uma nova concepção política, considerando esta como processo de criação do Direito. Mais uma vez, o contrato favorece a coletividade por dar a ela espaço político no sentido anteriormente pontuado.

Entretanto, apesar da relevância social demonstrada, Gagliano e Pamplona Filho ${ }^{12}$ são categóricos ao afirmar que o "Código Civil de 1916 ignorou a função social do contrato e da propriedade". Não se poderia esperar algo diferente, afinal, como dizem os mesmo doutrinadores, o diploma civil possuía "nítida vocação materialista" e um "firme propósito de tutelar o crédito e a propriedade".

\section{A FUNÇÃO SOCIAL DOS CONTRATOS}

Para se chegar à função social dos contratos e tratar de seus predicados deve-se ter em mente, antes de tudo, as bases sobre as quais esse

\footnotetext{
${ }^{9}$ BRANCO, Gerson Luiz Carlos, op. cit., p. 08.

${ }^{10}$ BRASIL. Lei no 3.071, de 1916 (revogada). Código Civil. Rio de Janeiro, RJ, Disponível em: 〈http://www.planalto.gov.br/ccivil_03/leis/L3071.htm〉. Acesso em: 28 set. 2015.

${ }^{11}$ BRANCO, Gerson Luiz Carlos, op. cit., p. 15.

${ }^{12}$ GAGLIANO, Pablo Stolze; PAMPLONA FILHO, Rodolfo, op. cit., p. 86.
} 
princípio emergiu. Estamos falando da propriedade e sua função social explicitamente contemplada pela Constituição de 1988, e a própria promulgação do novo Código Civil de 2002, que expressamente trouxe a função social dos contratos. Ainda é importante fazer referência ao processo que promove a interação dos dois diplomas supracitados: a constitucionalização do Direito Civil.

\subsection{A PROPRIEDADE ATRAVÉS DA CONSTITUIÇÃO DE 1988}

Primeiramente, deve-se atentar à estreita relação que o contrato e a propriedade guardam entre si. João Hora Neto, citado por Gagliano e Pamplona Filho ${ }^{13}$, refere-se à propriedade como o "segmento estático da atividade econômica", ao passo que o contrato seria a dimensão dinâmica. Assim, o pacto de vontades, nas palavras do mesmo autor, "é um instrumento poderoso da circulação [...] da própria propriedade". Se a propriedade sobre um uma coisa confere ao seu titular as faculdades de usar, gozar, dispor e reivindicar esse bem, é por meio dos contratos que um desses poderes reais - a disposição - pode ser exercido. Demonstrada toda essa afinidade entre os dois institutos, não é difícil perceber que os impactos sobre a propriedade refletem firmemente nos contratos, ou vice-versa.

No que tange à função social dos contratos, a disciplina jurídica que serviu de paradigma para o seu surgimento foi aquela dada pela Constituição de 1988, que em seu art. $5^{\circ}$, inciso XXIII, determina: "a propriedade atenderá a sua função social" 14 . Como visto, propriedade e contrato acompanham a sorte um do outro reciprocamente, logo, a socialização da propriedade só poderia conduzir a um processo: a socialização do contrato. Ressalve-se, contudo, que, como preleciona Giselda Hironaka, referida por Gagliano e Pamplona Filho ${ }^{15}$, "não se trata, sem sombra de dúvida, de se estar caminhando no sentido de transformar a propriedade em patrimônio coletivo da humanidade, mas tão apenas de subordinar a propriedade privada aos interesses sociais".

\footnotetext{
13 Ibidem, p. 50.

${ }^{14}$ BRASIL. Constituição (1988). Constituição da República Federativa do Brasil de 1988. Brasília, DF, Disponível em: <http://www.planalto.gov.br/ccivil_03/constituicao/constituicaocompilado.htm>. Acesso em: 28 set. 2015.

${ }^{15}$ GAGLIANO, Pablo Stolze; PAMPLONA FILHO, Rodolfo, op. cit., p. 81.
} 


\subsection{A CONSTITUCIONALIZAÇÃO DO DIREITO CIVIL}

Esse processo se dá, em suma, "pela vinda de normas de direito civil para a Constituição como, sobretudo, pela ida da Constituição para a interpretação do direito civil, impondo um novo conjunto de valores e princípios" "16. Insere-se dentro de uma conjuntura de superação da velha dicotomia entre o direito público e privado, que dá lugar a uma sobreposição de um ramo sobre o outro.

O entendimento a respeito da Constituição passou por uma transformação, pela qual a Carta Magna deixa de ser uma coletânea de enunciados meramente orientadores e passa a ter força normativa da mesma magnitude - ou até maior - que as leis infraconstitucionais. A partir disso, os princípios e regras constitucionais plasmam e condicionam todo o ordenamento jurídico. O princípio da dignidade da pessoa humana, por exemplo, elencado pela Constituição como um fundamento da República brasileira em seu art. $1^{\circ}$, III, na posição de valor-síntese para o qual convergem todos os demais, "promove uma despatrimonialização e uma repersonalização do direito civil"17.

\subsection{O CÓDIGO CIVIL DE 2002}

Segundo Santos ${ }^{18}$, atribui-se a Miguel Reale, coordenador e sistematizador do Código Civil de 2002, "o rompimento do individualismo que ainda permeava o Código de 1916". Ruptura essa que tem origem na constitucionalização do Direito Civil, que deslocou a preocupação do diploma civil centrada no "ter" para privilegiar o "ser" (despatrimonialização e repersonalização), o que se tornou evidente na pela adoção dos chamados princípios norteadores do hodierno código. São eles:

\footnotetext{
${ }^{16}$ BARROSO, Luís Roberto, op. cit., p. 395.

${ }^{17}$ Ibidem, p. 397.

${ }^{18}$ SANTOS, Antonio Jeová, op. cit., p. 95.
} 
a) Eticidade: impõe a compatibilização de valores técnicos, fortemente presentes no Código antecedente, com valores éticos, suplantando, assim, a inclinação ao formalismo jurídico.

b) Operabilidade: proporciona maiores poderes hermenêuticos ao magistrado por meio da normatização via cláusulas gerais, as quais exigem que sejam conformadas no caso concreto.

c) Sociabilidade: representa a superação do paradigma individualista e patrimonialista reinante durante a vigência da codificação de Beviláqua em favor da coletividade. É desse princípio que diretamente decorre a positivação da função social do contrato no art. 421 do diploma civil vigente: "A liberdade de contratar será exercida em razão e nos limites da função social do contrato" 19 .

\subsection{A FUNÇÃO SOCIAL PROPRIAMENTE DITA}

Pela redação do art. 421 acima transcrita, tem-se que o princípio da função social dos contratos foi qualificado sob dois critérios: um finalístico ou teleológico ("em razão") e outro limitativo ("nos limites"). O primeiro indica que o contrato encontra fundamento ou razão de ser na função social desempenha; o segundo já quer denotar que a liberdade contratual deverá ter como limite o interesse social e os valores consubstanciados no princípio maior da dignidade humana, sem os quais o pacto incorre em abuso $^{20}$.

Borges ${ }^{21}$ vai além e enxerga no princípio duas dimensões: um aspecto interno e outro externo. A primeira dimensão representa a vedação à prática do abuso por uma das partes em desfavor do outro contraente, de modo que faça o contrato servir a apenas um dos polos, deixando de satisfazer os interesses de um dos sujeitos, o que importa na destituição de sua justificativa jurídica e social.

$\mathrm{O}$ segundo aspecto destacado pela autora diz respeito à proibição de contratos que venham a causar danos a pessoas externas ao vínculo contratual, por mais que esta relação tenha se constituído através do mais

19 BRASIL. Lei $\mathrm{n}^{\circ}$ 10.406, de 2002. Código Civil. Brasília, DF, Disponível em: <http://www.planalto.gov.br/ccivil_03/leis/2002/L10406.htm>. Acesso em: 28 set. 2015.

${ }^{20}$ GAGLIANO, Pablo Stolze; PAMPLONA FILHO, Rodolfo, op. cit., p. 89-90.

${ }^{21}$ BORGES, Roxana Cardoso Brasileiro, op. cit. 
perfeito pacto de vontades entre os contraentes. Portanto, através dessa dimensão tem-se a "triangulação da relação contratual": os dois polos contratantes e os terceiros, isto é, a coletividade, que passa a ter seus direitos protegidos contra acordos que ultrapassem os limites da função social.

Essa tutela pode ser assegurada, por exemplo, pela aplicação articulada dos arts. 187 e 421 do Código Civil vigente, por meio dos quais se verifica que a extrapolação dos limites da função social equipara-se a uma ilicitude, pois representa abuso do direito de contratar, logo, vindo este ato antijurídico a causar danos, enseja a responsabilização dos contraentes, que passam a contrair a obrigação de reparar os prejuízos a que deram causa. Assim, maculadas tanto a sua função interna quanto a externa, o negócio é eivado por problemas quanto a sua validade e eficácia.

Por fim, arrematando-se a questão de maneira sintética e fazendo uso mais uma vez da brilhante doutrina de Gagliano e Pamplona Filho ${ }^{22}$, o contrato que observa as exigências da sua função social é aquele que:

a) Reverencia a dignidade da pessoa humana;

b) Acata a relativização do princípio da igualdade das partes contratantes, atentando que os acordos de fato paritários, hodiernamente, representam uma parcela bem menor no universo dos contratos;

c) Acolhe uma cláusula implícita de boa-fé objetiva, pela qual se torna impositivo a observância dos deveres associados de lealdade, confiança, assistência, confidencialidade e informação;

d) Respeita o valor social do trabalho;

e) Poupa o meio ambiente.

\section{A DIMENSÃO SOCIOAMBIENTAL DOS CONTRATOS}

Como bem alerta Borges ${ }^{23}$, propor uma função socioambiental não se trata de formular um conceito ambiental do contrato, muito menos de insinuar uma obsolescência da atual compreensão desse instituto, mas tão-somente por holofote sobre a variável ambiental que há - ou pelo

22 GAGLIANO, Pablo Stolze; PAMPLONA FILHO, Rodolfo, op. cit., p. 51.

${ }^{23}$ BORGES, Roxana Cardoso Brasileiro. Reconstruindo o Direito Civil a partir do Direito Ambiental: contrato, bem, sujeito . Revista do Programa de Pós-Graduação em Direito da UFBA. Salvador, n.14, p.97-128, jun. 2007. 
menos deve haver - nos negócios jurídicos. Essa necessidade de colocar em relevo o fator relacionado do meio ambiente é justificada pela inegável crise ecológica que se vivencia em nosso tempo, bem como é impulsiona pelo entendimento transindividual e intergeracional que se tem a respeito do direito ao meio ambiente.

\subsection{A CRISE ECOLÓGICA E OS CONTRATOS}

A sociedade capitalista e vocacionada para o consumo excessivo tem na crise ecológica o preço a ser pago pelo seu modelo de vida. Desastres naturais, falta de água potável, desertificação, poluição atmosférica, fluvial e marinha, perda de biodiversidade, entre outros, são sintomas marcantes da ação inconsequente do homem sobre natureza. Nesse contexto nada agradável é que a humanidade - talvez tardiamente - busca desde o fim do século passado a solução que nos faça vislumbrar horizontes mais favoráveis.

No bojo dos esforços para reverter esse quadro, surgem conceitos que, hoje, são muito difundidos, tais como desenvolvimento sustentável e economia verde. Esses termos são verdadeiras orientações para o homem contemporâneo na condução de seus empreendimentos, desde tarefas simplórias dos dia-a-dia até deliberações de alcance mundial. Nada mais objetivam que a preservação da natureza aliada ao desenvolvimento social da humanidade, sem que para isso seja necessário reduzir a zero o crescimento econômico.

Tendo em vista que os contratos estão estreitamente relacionados com a dinâmica da economia, já que é o instrumento pelo qual a circulação de bens e serviços se dá dentro do mercado, não é difícil perceber o quão importante seria o alinhamento desse instituto com as políticas de proteção dos recursos naturais, de modo a incluir cláusulas que contemplassem a preocupação ecológica. Em consonância com essa visão, enfatiza Saldanha ${ }^{24}$ :

\footnotetext{
${ }^{24}$ SALDANHA, Alexandre Henrique Tavares. Função socioambiental dos contratos e instrumentalidade pró- sustentabilidade: limites ao exercício de autonomias públicas e privadas. Veredas do Direito: Direito Ambiental e Desenvolvimento Sustentável, Belo Horizonte, v. 8, n. 16, p.99-114, 2011. Disponível em: <http://www.domhelder.edu.br/revista/index.php/veredas/article/view/212/187>. Acesso em: 25 set. 2015.
} 
No contexto em que se preza pelo desenvolvimento sustentável, não somente a norma jurídica ambiental propriamente dita deve servir como instrumento no alcance de objetivos que estejam relacionados a este valor, devendo haver um uso comum de ferramentas jurídicas, novas ou velhas, voltado para o alcance da sustentabilidade. E é nesse contexto no qual não se deve falar apenas em função social das relações contratuais, e sim enfatizar seus fins socioambientais.

Configura-se como uma urgência, pois, o proveito da contribuição que pode ser dada pelos contratos na luta pela superação da crise ecológica em evidência, desde que esses instrumentos sejam reconsiderados no sentido de se realocar hierarquicamente os princípios que os cercam, em outras palavras, desde que se ponha como prioridade o atendimento ao princípio socioambiental.

\subsection{O DIREITO DIFUSO AO MEIO AMBIENTE}

A Constituição de 1988 consagra em seu art. 225 o direito ao meio ambiente ecologicamente equilibrado. A doutrina o classifica como um direito difuso ou transindividual, ou seja, em linhas gerais, aquele cuja titularidade não pode ser precisada. Constitui um interesse de toda a coletividade.

Borges ${ }^{25}$ defende que o direito em questão é "erga omnes em dois sentidos": ao mesmo tempo em que todos possuem o direito ao meio ambiente ecologicamente equilibrado, a todos os sujeitos, sejam públicos ou privados, é atribuído o dever de preservá-lo, isto é, essa obrigação não compete apenas ao Estado, como o próprio art. 225 deixar claro na sua segunda metade: "[...] impondo-se ao Poder Público e à coletividade o dever de defendê-lo e preservá-lo para as presentes e futuras gerações" 26 .

Do mesmo fragmento do artigo acima transcrito se depreende o caráter intergeracional desse direito pela parte que faz menção às "presentes e futuras gerações", que inevitavelmente remete ao próprio conceito de desenvolvimento sustentável. Percebe-se, portanto, que até mesmo os

\footnotetext{
${ }^{25}$ BORGES, Roxana Cardoso Brasileiro, op. cit., 2010.

${ }^{26}$ BRASIL. Constituição (1988), op. cit.
} 
grupos humanos vindouros fazem jus ao meio ambiente sadio e estável, fazendo com que a natureza difusa do direito em tela torne-se ainda mais acentuada. Desse modo, amplia-se o rol de motivos pelos quais o assunto merece uma tutela especial do ordenamento jurídico.

Devido ao elevado grau de proeminência que os valores ambientais atingiram, até mesmo um Estado Ambiental de Direito começa a ser projetado pelos estudiosos, já como o próximo estágio do Estado Democrático de Direito, o que naturalmente implica uma reconsideração da atuação do Poder Público, bem como uma nova forma de cidadania. Assim, Vicente Capella, mencionado por Borges ${ }^{27}$, enumera algumas características básicas dessa nova modalidade:

a) Natureza como principal instituição;

b) Todo ser humano é sujeito de direito;

c) Solidariedade como fim maior;

d) Destaque para os direitos fundamentais de terceira geração;

e) Proteção do meio ambiente como função principal.

O fato é que a discorrida transindividualidade do direito ao meio ambiente ecologicamente equilibrado vem a impactar na seara dos contratos na medida em que atrai para a relação negocial sujeitos estranhos a esse vínculo, mas que, todavia, têm no possível dano ao meio ambiente a motivação necessária para tomar as providências cabíveis para movimentar a máquina pública, que, judicial ou extrajudicialmente, deverá resguardar o direito inobservado pelo contrato abusivo, momento a partir do qual esses terceiros equiparam-se às partes, já que por essa via é possível, inclusive, a revisão do pacto transgressor ${ }^{28}$.

\subsection{A FUNÇÃO SOCIOAMBIENTAL PROPRIAMENTE DITA}

Tendo em mente os pressupostos abordados nos subtópicos anteriores, parte-se agora para analisar os contornos mais específicos da função

\footnotetext{
${ }^{27}$ BORGES, Roxana Cardoso Brasileiro, op. cit., 2010.

${ }^{28}$ Ibidem.
} 
socioambiental dos contratos, que nada mais significa que um redimensionamento da função social.

A aludida função, frise-se, pelo ensinamento de Saldanha ${ }^{29}$ :

[...] eleva a figura do particular como agente ativo da transformação necessária para a sustentabilidade, demonstrando que a responsabilidade de prezar pelo uso racional do meio ambiente e de se preocupar com o sistema ecológico não é exclusiva dos entes públicos, mas de todos.

Destarte, o aspecto ambiental desse princípio impõe aos contraentes um dever ainda maior de proteção ao meio ambiente, sendo por isso personagens-chave na consecução do desenvolvimento sustentável, já que têm em mãos um importante instrumento que sofre e exerce, simultaneamente, grande influência no âmbito da economia.

Descumpre, portanto, os preceitos estabelecidos pelo princípio da função socioambiental o contrato que estipula e rege atividades causadoras de deterioração da natureza, atingindo, assim, um sem número de indivíduos devido, como já explicado, ao caráter difuso do direito consagrado pelo art. 225 da Constituição. A satisfação dos interesses dos sujeitos contratantes não pode se dar através da externalização integral do custo ambiental, ou seja, todo impacto sobre o meio ambiente deve ser controlado de forma a lesar o mínimo possível a natureza e, consequentemente, a sociedade.

Por conseguinte, o dano ao bem jurídico alheio, qual seja, o meio ambiente ecologicamente equilibrado, enseja a responsabilização dos contraentes. E, como pontua Borges ${ }^{30}$, "a regra, no Direito Ambiental brasileiro, sobre a responsabilidade pelo dano ambiental é a solidariedade entre os poluidores", isto é, por também dar causa ao prejuízo ambiental a parte que ambiciona os proveitos econômicos da atividade poluidora sem, contudo, executar materialmente ou diretamente a conduta geradora de poluição, aos dois contraentes é imputada a culpa pelo empreendimento lesivo ao meio ambiente. Essa é a interpretação que se depreende da leitura do

\footnotetext{
${ }^{29}$ SALDANHA, Alexandre Henrique Tavares, op. cit., p. 107.

${ }^{30}$ BORGES, Roxana Cardoso Brasileiro, op. cit., 2007.
} 
art. $3^{\circ}$, inciso IV, da Lei 6.938/81, que dispõe sobre a Política Nacional do Meio Ambiente ${ }^{31}$.

São variados e conhecidos os meios jurídicos pelos quais se pode garantir a observância da função socioambiental pelos contratos. Além da ação popular, do mandado de segurança e do mandado de injunção, no que couberem, tem-se o termo de ajustamento de conduta e a ação civil pública como os mecanismos mais eficientes.

Tomando-se como referência este último meio, que foi instituído pela Lei 7.347/85, inicialmente tem-se que apenas os sujeitos elencados nos incisos de I a V do art. $5^{\circ}$ da mesma legislação estão aptos a suscitar a função socioambiental dos contratos, porém, avançando um pouco mais na leitura da lei e chegando-se ao seu art. $6^{\circ}$, que determina que "qualquer pessoa poderá e o servidor público deverá provocar a iniciativa do Ministério Público, ministrando-lhe informações sobre fatos que constituam objeto da ação civil e indicando-lhe os elementos de convicção" ${ }^{2}$, entendese que há uma abertura para que a sociedade em geral, pelo menos indiretamente, também possa promover, de certa forma, a função contratual em debate. Por fim, ressalte-se a valiosa observação de Borges ${ }^{33}$ ao dizer que:

O pedido [da ação civil pública] pode visar à reparação do dano ambiental, assim como à sua prevenção, podendo levar à revisão do contrato e alteração do pactuado para, por exemplo, dilatar o prazo de execução da obrigação, adiar o início da atividade em questão, diminuir a quantidade a ser produzida, diminuir o volume de certo componente, alterar o horário de atividade, aumentar o valor contratado, dentre outras providências necessárias, inclusive a rescisão do contrato, em casos de prejuízo extremo ao meio ambiente.

Saldanha ${ }^{34}$ igualmente destaca a importância de uma atividade jurisdicional atenta e alinhada aos valores ambientais, tidos com fundamentais pela Constituição da República Federativa do Brasil, para a

${ }^{31}$ BRASIL. Lei $n^{\circ}$ 6.938, de 1981. Política Nacional do Meio Ambiente. Disponível em: <http://www.planalto.gov.br/ccivil_03/Leis/L6938.htm>. Acesso em: 28 set. 2015.

32 BRASIL. Lei no 7.347, de 1985. Ação Civil Pública. Brasília, DF, Disponível em: <http://www.planalto.gov.br/ccivil_03/leis/L7347orig.htm>. Acesso em: 28 set. 2015.

${ }^{33}$ BORGES, Roxana Cardoso Brasileiro, op. cit., 2010.

${ }^{34}$ SALDANHA, Alexandre Henrique Tavares, op. cit., p. 110. 
concretização da dimensão ambiental dos contratos, de modo que o produto dessa atividade essencial, isto é, as decisões, transpareça uma "postura prósustentabilidade" do Estado-juiz.

\section{CONCLUSÃO}

Traçou-se no decorrer do presente estudo uma espécie de linha evolutiva de um dos institutos mais importantes do Direito Civil: o contrato, principalmente no que tange à sua função. Limitou-se o objeto da análise ao Direito pátrio, porém, para entendê-lo verdadeiramente dentro da lógica do Código Civil de 1916, primeiramente foi necessário buscar na legislação francesa pós-revolução o modelo contratual que foi importado pelo Código revogado. Da mesma forma, constituiria um erro muito grave partir diretamente para explicar a nova roupagem dada aos contratos pelo Código Civil de 2002 sem antes compreender pressupostos que fizeram nascer o princípio da função social. Procedeu-se igualmente quando se tratou da função socioambiental, já que se explicaram preliminarmente as razões pelas quais era forçoso o redimensionamento da função social dos acordos de vontades para somente depois abordar o princípio em si.

Verificou-se a grande sensibilidade dos contratos à conjuntura social da época em que está inserido, reproduzindo fielmente os valores eleitos em primeiro plano pela sociedade. O contrato do Código de 1916 é, portanto, liberal e individualista, sendo a expressão máxima da autonomia da vontade. Cumpre ele, por óbvio, uma função, mas que nem de longe se assemelha à função social consagrada pelo Código vigente, porquanto é útil à sociedade apenas na medida em que dinamiza as relações econômicas, fazendo jus, desse modo, ao excessivo caráter patrimonialista da lei civil ao tempo.

O contrato desenhado pelo Código Civil de 2002, por sua vez, traz, como visto, grande carga de sociabilidade, isto é, o negócio jurídico tem na função social apontada pelo art. 421 o seu fundamento e os seus limites, traduzindo uma sobreposição dos interesses coletivos em relação aos interesses particulares. Tal situação reflete, portanto, a irradiação dos princípios e regras constitucionais sobre o restante do ordenamento, processo pelo qual os direitos fundamentais, consubstanciados no princípio da dignidade humana, passam a ser observados não importando se o âmbito é público ou privado. 
Por último, explorou-se função socioambiental, que nada mais representa além da relevância crescente da faceta ambiental da função social, em razão, mais uma vez, da conjuntura da era que se examina, logo, as circunstâncias contemporâneas apontam para a crise ecológica, cujo enfrentamento passa inevitavelmente pela adoção de contratos alinhados com o pensamento ambiental. Não é caso, como apreendido, de elaborar um novo conceito de contrato, mas apenas de dar destaque ao seu fator ambiental. Salientou-se também que a emergência dessa dimensão ambiental do negócio jurídico muito deve à natureza difusa do direito ao meio ambiente ecologicamente equilibrado, que acaba por atrair á relação contratual pessoas estranhas ao vínculo contratual. A esses terceiros servem mecanismos jurídicos que possibilitam resguardar concretamente o direito consagrado pelo art. 225 da Constituição.

\section{REFERÊNCIAS BIBLIOGRÁFICAS}

BARROSO, Luís Roberto. Curso de Direito Constitucional Contemporâneo: Os conceitos fundamentais e a construção do novo modelo. 3. ed. São Paulo: Saraiva, 2012.

BORGES, Roxana Cardoso Brasileiro. Função ambiental do contrato: proposta de operacionalização de princípio civil para a proteção do meio ambiente. Revista de Direito Ambiental. São Paulo: Revista dos Tribunais, ano 13, n. 49, jan/mar, 2010.

Reconstruindo o Direito Civil a partir do Direito Ambiental: contrato, bem, sujeito . Revista do Programa de Pós-Graduação em Direito da UFBA. Salvador, n.14, p.97-128, jun. 2007.

BRANCO, Gerson Luiz Carlos. Função social dos contratos: interpretação à luz do Código Civil. São Paulo: Saraiva, 2009.

BRASIL. Constituição (1988). Constituição da República Federativa do Brasil de 1988. Brasília, DF, Disponível em: <http://www.planalto.gov.br/ccivil_03/constituicao/constituicaocompilado.htm>. Acesso em: 28 set. 2015.

. Lei $\mathrm{n}^{\circ}$ 10.406, de 2002. Código Civil. Brasília, DF, Disponível em: <http://www.planalto.gov.br/ccivil_03/leis/2002/L10406.htm>. Acesso em: 28 set. 2015.

Lei no 3.071, de 1916 (revogada). Código Civil. Rio de Janeiro, RJ, Disponível em: <http://www.planalto.gov.br/ccivil_03/leis/L3071.htm>. Acesso em: 28 set. 2015.

. Lei $\mathrm{n}^{\circ}$ 6.938, de 1981. Política Nacional do Meio Ambiente. Disponível em: <http://www.planalto.gov.br/ccivil_03/Leis/L6938.htm>. Acesso em: 28 set. 2015. 
Lei no 7.347, de 1985. Ação Civil Pública. Brasília, DF, Disponível em: <http://www.planalto.gov.br/ccivil_03/leis/L7347orig.htm>. Acesso em: 28 set. 2015.

GAGLIANO, Pablo Stolze; PAMPLONA FILHO, Rodolfo. Novo Curso de Direito Civil: Contratos: teoria geral. 9. ed. São Paulo: Saraiva, 2013. 4 v.

SALDANHA, Alexandre Henrique Tavares. Função socioambiental dos contratos e instrumentalidade pró- sustentabilidade: limites ao exercício de autonomias públicas e privadas. Veredas do Direito: Direito Ambiental e Desenvolvimento Sustentável, Belo Horizonte, v. 8, n. 16, p.99-114, 2011. Disponível em: $\quad<$ http://www.domhelder.edu.br/revista/index.php/veredas/article/view/212/187>. Acesso em: 25 set. 2015.

SANTOS, Antonio Jeová. Função social do contrato: lesão e imprevisão no CC/2002 e no CDC. 2. ed. São Paulo: Método, 2004.

TARTUCE, Flávio. Teoria Geral dos Contratos: Os princípios contratuais no Código Civil de 2002. In: .Direito Civil: Teoria Geral dos Contratos e Contratos em espécie. 8. ed. São Paulo: Método, 2013. Cap. 2. p. 51-131. 